\title{
Rethink weight limits on morning-after pill
}

I ' $m$ no stranger to the late-night emergency contraceptive run. I'm married, accidents happen, and I don't want to take any chances. But the last time I tried to buy Plan B - one of four levonorgestrel "morning-after" pills sold in Canada - the pharmacist at my local drugstore turned me away.

I can't sell you this, she said. Have you heard about the weight limit? Health Canada says this won't work if you weigh more than 165 pounds. (That's not exactly what the regulator says, but more on that later.)

I hadn't heard about a limit, or told her my weight for that matter. Given that Health Canada has rated levonorgestrel as a Schedule III drug, I should be able to purchase it off the shelf without consulting a pharmacist. I asked the pharmacist about the strength of evidence for the recommendation, or if my body mass index (BMI) mattered, and since she didn't know, I asked to buy the pill anyway. She told me to see a doctor and asked to serve the next customer. I bought the pill from the drugstore down the road, where the pharmacist didn't mention a weight limit.

Both interactions were troubling either the first pharmacist was misinformed or the second had sold me a drug that wouldn't work. As it turned out, such situations are not uncommon. Dr. Edith Guilbert, a senior medical advisor for the Institut national de santé publique du Québec, has heard similar reports of Quebec pharmacists refusing to sell levonorgestrel to heavier women. She says these incidents are unjustified given the lack of consensus on the impact of body weight on the drug's efficacy.

"It might be less effective for women who weigh more than 165 pounds or have a BMI over 25, but to say there will be no efficacy is wrong, because we have no baseline statistics on the risk of pregnancy in women who are consulting for emergency contraception," explains Guilbert, who is co-chair of the Canadian Consensus on Contraception at the Society Obstetricians and Gynaecologists of Canada.

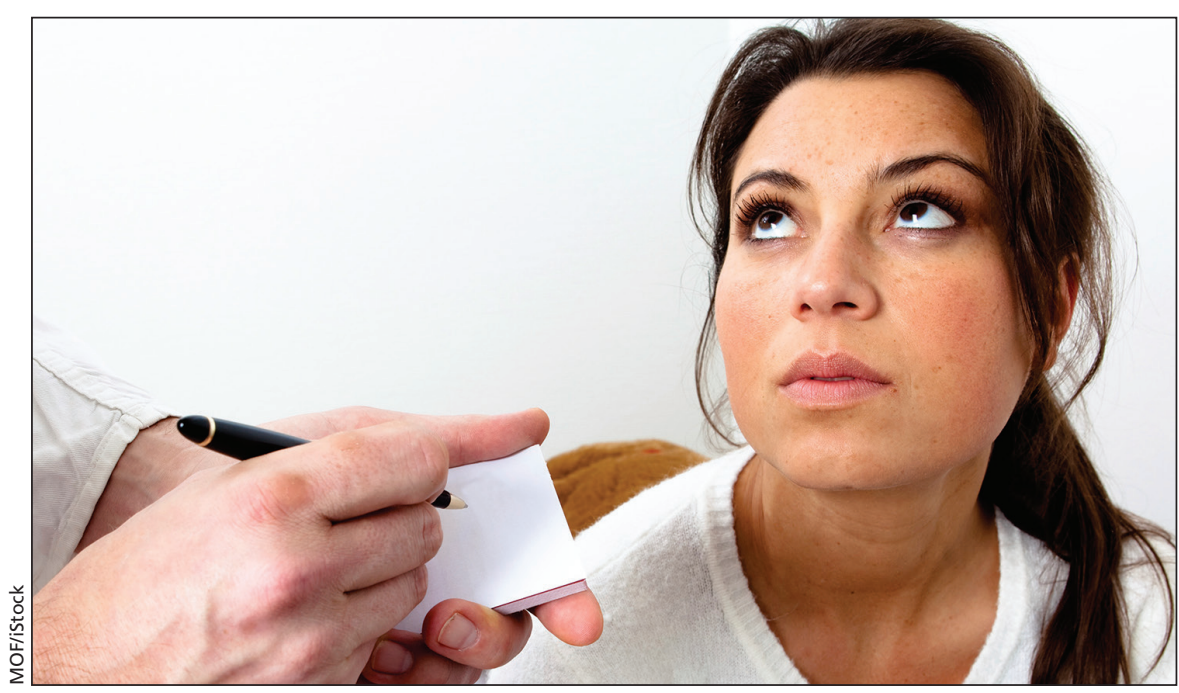

Health Canada recommendations on emergency contraception and body weight unduly limit "morning-after" options for many women, say experts.

Health Canada is the only regulator that currently recommends overweight and obese women seek alternative methods of emergency contraception, stating that levonorgestrel may be less effective in women over 165 pounds and ineffective in women over 176 pounds. This potentially represents more than half of all Canadian women over 18. The warning, issued in March 2014, is based on a 2011 meta-analysis that showed that obese women taking the drug had a fourfold greater risk of pregnancy than women of normal weight.

However, a European Medicines Agency review later in 2014 determined that the "data available are too limited and not robust enough to conclude with certainty that contraceptive effect is reduced with increased bodyweight." The agency advised women to continue using levonorgestrel regardless of their weight, ideally "as soon as possible" after unprotected sex in order to increase the likelihood that the drug will work.

The Society of Obstetricians and Gynaecologists of Canada has taken a similar stance, recommending that, until better evidence is available, women with a BMI over 30 "should not be discouraged" from using levonorgestrel if they can't access or don't want a copper intrauterine device (IUD) — the only alternative emergency contraceptive available in Canada.

This stance is also endorsed by the Canadian Pharmacists Association, according to Director of Pharmacy Innovation Phil Emberley. He says reports of women being denied levonorgestrel are concerning, and likely a product of "murky" guidelines on the issue. "We don't know the degree to which efficacy drops off based on weight; we don't have hard and fast milestones to go by."

Emberley also notes that it's rare for a single study to merit a sea change in practice. "Usually it's a body of evidence over time that moves clinical decision-making in a certain direction."

At the same time, "pharmacists are responsible for the medication they sell in their dispensaries and part of that responsibility is educating the public on how to use those drugs appropriately." Such counselling should ideally happen in private, he adds. And in the case of "off the shelf" drugs, any final decision should rest with the customer.

More evidence is needed to justify a refusal, particularly given the short time women have to access other forms of contraception, says Emberley. 
Right now, a woman turned away from her pharmacist has only one option for emergency contraception: getting a copper IUD inserted into her uterus by a physician. Copper IUDs are more than $99 \%$ effective at preventing pregnancy, but they can be expensive (up to several hundred dollars) and finding a doctor to insert the device within the recommended 120 hours can be difficult. One American study shows $85 \%$ of clinicians never recommend the device for emergency contraception, and $93 \%$ required two or more visits for an insertion.
The intimate nature of insertion, and the fact that IUDs can cause heavier, longer and more painful periods, also means the device isn't appropriate for everyone, says Guilbert.

A new emergency contraceptive drug, ulipristal acetate, will become available in Canada under the brand name Ella in the fall this year. The drug is currently available as an emergency contraceptive in Europe and the United States. There's evidence it's also more effective than levonorgestrel for women with a BMI over 30, says Guilbert. "The risk of unintended pregnancy is much less, like $2.5 \%$, compared to almost $6 \%$ for women using levonorgestrel."

However, the introduction of Ella won't dramatically improve access to emergency contraception for heavier women, as the drug will only be available by prescription. "It could take one or two years before it can become over the counter," explains Guilbert. In the meantime, "Health Canada should withdraw their recommendations regarding weight and levonorgestrel." — Lauren Vogel, CMAJ

CMAJ 2015. DOI:10.1503/cmaj.109-5098

\section{Why the fuss over disclosure of physician billings?}

$\mathrm{D}$ isclose the names, implored the Information and Privacy Commissioner of Newfoundland and Labrador. Do not disclose the names, ruled the Nova Scotia Court of Appeal. Disclose the names, ordered the United States government, ending more than 30 years of legal battles over whether the names should be disclosed.

The locations may change but the struggle remains the same. If you ask for physicians' billing data - with names for government-funded medical services, don't expect to get them without a fight.

But why do most medical associations work so hard to keep this information private? Is it really that big of a deal? After all, there are places, such as British Columbia and Manitoba, where physicians' medicare billings have been public knowledge for decades. Has the medical profession in these areas actually suffered as a result?

"I think most people will fight against other people looking at their salaries until it has been made public," said Kevin McNamara, former deputy minister of health and wellness for Nova Scotia. "But I think that after a year or two, it doesn't matter anymore."

Indeed, many of the oft-repeated arguments about disclosure appear to be more about principles and anomalies than widespread harms or benefits. Those in favour say it's about transparency and accountability in a health system funded with public money, and also about sussing out the few who are defrauding the system. Those against disclosure say it's an invasion of privacy, will be used to embarrass productive doctors and doesn't take into account the cost of staff, equipment and other overhead.

In Canada, one argument often made by medical associations against disclosing individual billings is that it will be used by provincial governments as leverage in contract negotiations with physicians. If negotiations break down, naming and shaming the highest earners becomes an option. That concern is not unfounded, according to Graham Steele, former finance minister for Nova Scotia.

There are legitimate arguments to be made for greater transparency in any negotiation or discussion about physician pay, said Steele. Physician remuneration consumes a huge amount of provincial budgets but receives little public discussion, he said. "If the facts are only known to insiders, you can't have a sensible public debate."

Still, acknowledged Steele, it often comes down to politics. In 2006, Steele, a lawyer by training, was involved in a court case that pushed for the release of individual physician billings. The court decided, that existing freedom-of-information laws did not require this information be made available. In the end, said Steele, it didn't really matter.

"Let's be frank, the public doesn't care, not in the sense of people getting worked up, but the doctors were very worked up."
If the judge had ruled in favour of disclosure, though, would it have given the province the upper hand, a weapon to shame "million-dollar" doctors and win public support for cuts to medical fees? Again, let's consider BC and Manitoba. Has it made a difference in those provinces? Well, if you're looking for evidence, you won't find any, says Jeremiah Hurley, the chair of economics at McMaster University and a member of the Centre for Health Economics and Policy Analysis.

In his opinion, this information doesn't have a big impact on negotiations. "I have no reason to believe that $\mathrm{BC}$ physicians are paid a lot less because it is published."

In $\mathrm{BC}$, the gross medicare billings of all doctors have been publicly available since 1971 in the Blue Book. Although, politicians and reporters tend to be among the most interested in the Blue Book, physicians are also quite curious about its contents. "It does breed some resentment," said Dr. David Attwell, president of the statutory negotiating committee for Doctors of BC.

Public disclosure of physician billings doesn't appear to discourage doctors from seeking work in the province. "but it does have a negative impact on morale," said Attwell. "The high-billers are just going to take cover and ignore it. The low-billers read it and may misinterpret it." - Roger Collier, CMAJ

CMAJ 2015. DOI:10.1503/cmaj.109-5044 